\title{
AC 2007-519: SITE ANALYSIS AND ENVIRONMENTAL RESTORATION
}

\section{Adrian Miron, University of Cincinnati}

Dr. Adrian Miron received his B.S. and M.S. in Applied Physics from University of Bucharest and his M.S. and Ph.D. in Nuclear Engineering from University of Cincinnati (UC). He is a research professor within the Mechanical, Industrial and Nuclear Engineering Department at UC, where he has developed and taught graduate core courses and has conducted research on various nuclear and radiological engineering topics. Previously, Dr. Miron worked at Argonne National Laboratory in the Diagnostic and Control Group within the Nuclear Engineering Division, and collaborated closely with the RESRAD team within the Environmental Science Division. His area of expertise includes: nuclear and radiological engineering; signal processing; emergency planning; and computer code development and testing. His accomplishments include: development and implementation of national nuclear emergency plans and technical procedures; contribution to methodology for dose assessment following a potential RDD event; signal reconstruction through wavelet-based signal de-noising; stochastic and deterministic process modeling; uncertainty analysis and statistical applications for improving fault detection and on-line monitoring.

\section{Eugene Rutz, University of Cincinnati}

Eugene Rutz is Academic Director in the College of Engineering at the University of Cincinnati. Eugene's responsibilities include new program development, distance learning program development, and evaluation of instructional technologies. He has a BS in Nuclear Engineering and an MS in Mechanical Engineering and is a registered professional engineer. Eugene has worked in the nuclear power industry, as a design engineer, and as a university researcher and instructor.

\section{Pradosh Ray, Tuskegee University}

Pradosh Ray received his Ph.D. degree in Nuclear Engineering from Pennsylvania State University. He has been teaching at Tuskegee University for thirty years. He is currently serving as Head of the Mechanical Engineering Department. His research interests are in electric rocket propulsion. He has also spent over twenty five years in course, curriculum, and laboratory development. 


\title{
Site Analysis and Environmental Restoration
}

\begin{abstract}
Tuskegee University (TU), in collaboration with University of Cincinnati (UC), has been engaged in the development of a two course sequence to educate students in environmental restoration/waste management (ER/WM). The course sequence is: 1) Introduction to Radiological Engineering and Waste Management and 2) Site Analysis and Environmental Restoration.

The content of the first course is consistent with current health physics courses with additional material on nuclear wastes. We consider the second course to be a unique course on analysis, characterization and remediation techniques of sites contaminated with radioactive material. The contents of the second course and course evaluation methods are described in this paper.
\end{abstract}

\section{Introduction}

The activities associated with nuclear weapon production have generated large amounts of radioactive wastes ${ }^{1}$. There has been widespread contamination of land and water around the disposal and storage sites of these wastes. Therefore, remedial actions must be included in any waste management plan.

Environmental restoration includes evaluating the environmental damage of a site, characterizing the environmental hazards, and cleaning up the site. After the clean up process is complete, the land and water needs to be certified as environmentally clean by all appropriate federal, state, and local environmental regulatory agencies ${ }^{2}$. Hence, knowledge of current environmental laws and regulations and appropriate codes developed by DOE national laboratories and federal agencies is required.

Trained manpower with an education in science and engineering is needed to successfully tackle the technologically challenging problem of ER/WM. Unfortunately, there is a shortage of students with this background in the United States due to a declining interest among high school students, particularly African Americans, to be engaged in these disciplines.

In view of this, TU, in collaboration with UC, has developed a two course sequence and associated summer training and research programs in ER/WM to educate and train African American undergraduate students. UC's role in these activities has been to provide technical expertise and guidance in the development of these courses and associated summer training and research programs. 


\section{Course Description}

The courses developed by us are: 1) Introduction to Radiological Engineering and Waste Management (MENG 493E) and 2) Site Analysis and Environmental Restoration (MENG 493F). The first course was developed in Fall 2005 semester and offered at TU as a 3-credit hour elective course during Spring 2006 semester. The second course was developed in Fall 2006 semester and offered at TU as a 3-credit hour elective course during Spring 2007 semester.

The first course focused on elements of radiological engineering, dose assessment, fuel cycle, and waste management ${ }^{3}$. The second course deals with analysis, characterization and remediation techniques of sites contaminated with radioactive material. It also includes radioactivity, radiation interaction with matter and radiation dose as students in this course had no prior exposure to any basic nuclear radiation course. Juniors/seniors from biology, chemistry, environmental science, physics and all engineering disciplines were eligible to take this course. Six students were enrolled in this course.

About one third of the course was specifically devoted to environmental laws, regulations, site analysis, and environmental restoration. Students were introduced to the current guidance for planning, implementing, and evaluating environmental and facility radiological surveys conducted to demonstrate compliance with a dose- or risk-based regulation. We accomplished this by presenting elements of the Multi-Agency Radiation Survey and Site Investigation Manual (MARSSIM) developed under the auspices of several federal agencies to provide a single, nationally consistent guide for verifying that radioactively contaminated sites have been cleaned up to required standards. In addition, the US Environmental Protection Agency (EPA) Superfund Program containing guidance on how to design and conduct consistently and technically-defensible ecological risk assessments were also introduced to the students. Several codes such as COMPASS, CAP88, and RESRAD family of codes were reviewed and students were offered the opportunity to solve simple problems by running the CAP88 code.

We believe this sequence would better prepare and train the students for both engaging in activities related to ER/WM, as well as creating the basic knowledge for those who would like to pursue graduate studies in this field. In addition, we believe that the handson experience on running appropriate codes and the section on environmental site analysis and regulations are unique not only to historically black colleges and universities but also to US academic programs that teach core curricula and research programs on this subject.

The contents of the course are described below.

\section{$\underline{\text { Site Analysis and Environmental Restoration }}$}

a. Radioactivity - The process of radioactive decay; Half-life and activity, Important radioisotopes in wastes and contaminated environment -6 lectures 
b. Radiation Interaction with Matter - Alpha, beta, gamma, and neutron rangeenergy relationships; Interaction mechanisms - 6 lectures

c. Biological Effects of Radiation - Radiation Dose Units, Dose calculations - 8 lectures

d. Classification of Wastes - High-level, transuranic, and low-level wastes, Disposal of wastes -6 lectures

e. Health, Safety, and Environmental Protection - Radiation pathways analysis; Radiation safety guidelines, Risk assessment -5 lectures

f. Site Analysis and Restoration - Knowledge of federal codes, Environmental restoration -8 lectures

\section{Course Evaluation}

The course outline given to students at the beginning of the class lists several objectives for the course. These objectives indicate several important ideas that students should master at the end of the course. Each objective contains one or more key concepts that students should learn which in turn will enable them to master these objectives. Each course objective is then mapped to one or more program educational outcomes as defined by the Accreditation Board for Engineering and Technology (ABET).

Since this course was on-going when this paper was written, we will use the data gathered from the first course to indicate how courses are evaluated at TU. For the first course (MENG 493E), the objectives are that at the end of the course students will:

1. learn about the concepts of radioactive decay and radiation interaction with matter;

2. understand about the biological effects of radiation;

3. be able to calculate radiation dose; and

4. learn about the laws governing disposal of nuclear wastes.

\section{Concepts:}

The following concepts were covered within each objective:

Objective 1:

Concept 1 --- Radioactive decay, half-life

Concept 2 --- Radiation attenuation

Objective 2:

Concept 3 --- Radiation dose units

Objective 3: 
Concept 4 --- Dose calculation methods

Objective 4:

Concept 5 --- Laws, regulations, and organizations

For this course, the course objective to program educational outcome mapping is shown in Table 1.

Table 1: Mapping of MENG 493E course objectives to program outcomes

\begin{tabular}{|l|c|c|c|c|c|c|c|c|c|c|c|}
\hline Outcomes & a & b & c & d & e & f & g & h & i & j & k \\
\hline Objective 1 & $\mathrm{x}$ & & & & $\mathrm{x}$ & & & & & & \\
\hline Objective 2 & $\mathrm{x}$ & & & & $\mathrm{x}$ & & & & & & \\
\hline Objective 3 & $\mathrm{x}$ & & & & $\mathrm{x}$ & & & & & & \\
\hline Objective 4 & & & & & & $\mathrm{x}$ & & & & & \\
\hline
\end{tabular}

Course objectives 1-3 address criterion a): an ability to apply knowledge of mathematics, science, and engineering and criterion e): an ability to identify, formulate, and solve engineering problems. Course objective 4 addresses criterion f): an understanding of professional and ethical responsibility.

Throughout the semester, the instructor assessed if students were learning these concepts from the tests that were periodically administered. These assessments were put in a scale of 1 (poor) to 5 (excellent) for each student. At the end of the course, average of student scores for each objective was determined to assess whether the student body in the class was able to master that particular objective.

At the end of the class, students were also asked to evaluate if they feel that they have learned these concepts on the same 1 to 5 scale. The purpose of this exercise was to find out if there was any serious discrepancy between the assessment of the instructor and the self-assessment of students. The student self-assessments are also averaged over the class for each objective. The two assessments for each objective were then compared by the instructor.

The course assessment results for the MENG 493E course for the Spring 2006 semester are presented in Figure 1. Only the first four concepts have been evaluated due to time constraints. 


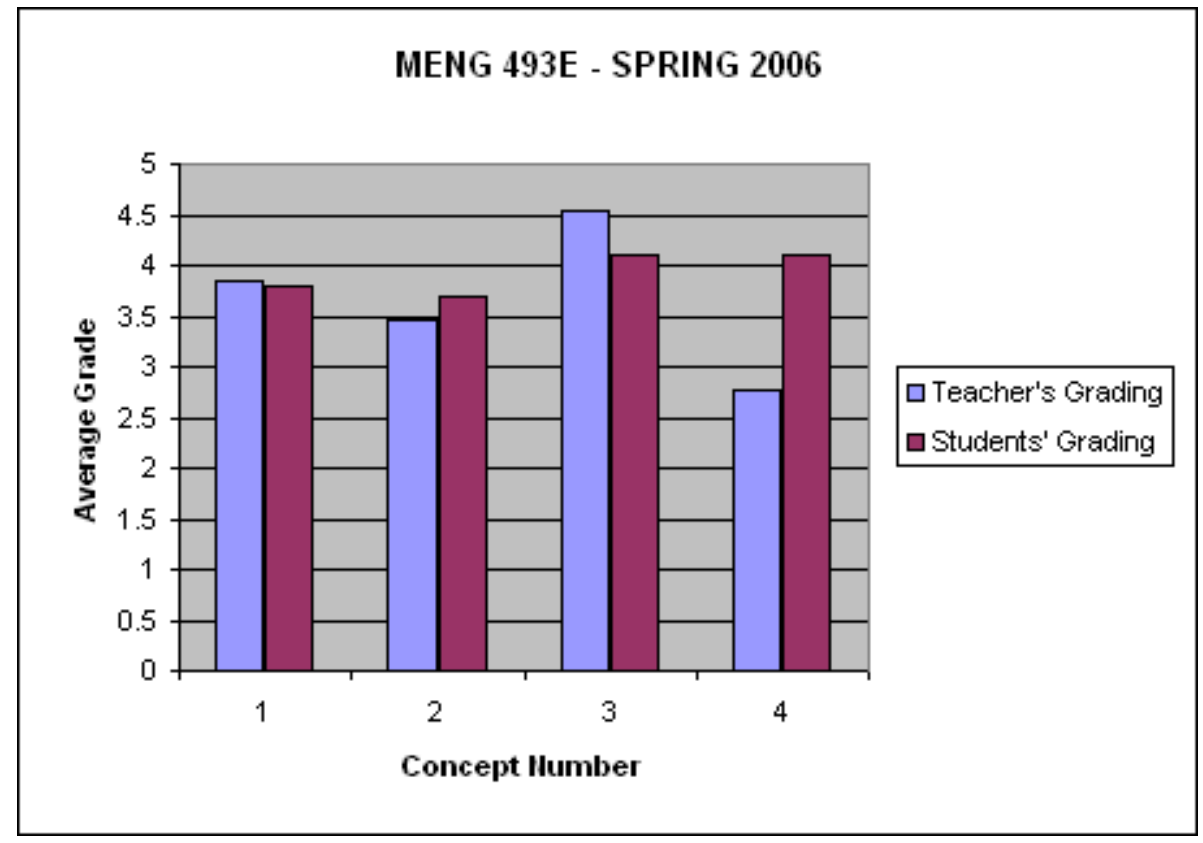

Figure 1: Faculty and student assessment results for the MENG 493E course in the Spring 2006 semester

It can be seen from Fig. 1 that concept 4, dose calculation methods, shows the largest discrepancy between teacher's and students' assessments of learning this concept. It was found that that the instructor was unable to dedicate adequate time to cover this concept. More time will be devoted to this topic when the course is offered next time.

\section{Conclusion}

This paper describes an educational program being developed on ER/WM that is geared toward National Nuclear Security Administration (NNSA) goals. Undergraduate students from science and engineering disciplines can take these courses for credit towards their degrees. At the end of each year, many African American students will graduate with a cross disciplinary knowledge of ER/WM. 


\section{References}

1. US Department of Energy, National TRU Waste Management Plan DOE/NTP-96-1204, Revision 2, December 2000.

2. Multi-Agency Radiation Survey and Site Investigation Manual (MARSSIM), Rev. 1, August 2002.

3. Miron, A., Rutz, E. and Ray, P., "Introduction to Radiological Engineering and Waste Management", Presented at the ASEE Annual Conference, Chicago, 2006. 